\title{
Malignant Cardiac Neoplasm
}

National Cancer Institute

\section{Source}

National Cancer Institute. Malignant Cardiac Neoplasm. NCI Thesaurus. Code C3548.

A primary or metastatic malignant neoplasm involving the heart. 